\title{
Improvement of operation modes of water treatment systems using baromembrane technologies
}

\author{
Ekaterina Samarkina $^{1, *}$, Anna Gudzenko ${ }^{1}$, Svetlana Bondarenko $^{1}$, and Anastasia Samarkina ${ }^{2}$ \\ ${ }^{1}$ Irkutsk National Research Technical University, 664074, Lermontova str., 83, Irkutsk, Russia \\ ${ }^{2}$ Baikal State University, 664003, Lermontova str., 11, Irkutsk, Russia
}

\begin{abstract}
The paper touches upon the issues connected with the solutions of the problems arising at operation of membrane installations for water preparation, in particular high water consumption for own needs. The reasons leading to their occurrence are analyzed in the article. A comparison of the performance of membrane systems against the calculated values is made. The influence of aging of membranes on water consumption for own needs is studied. The tests of a membrane element have been carried out on a laboratory installation, the results of which are used for the analysis of the chemical contamination. The options of solving the identified problems are proposed.
\end{abstract}

\section{Introduction}

For the time being, the need for clean water is growing rapidly throughout the world. At the same time, increasing cost of water treatment in housing and communal services, individual housing construction, and also in various industries leads to the need to search for modern, efficient, compact, and easy-to-use methods of water treatment. Such methods of water preparation include membrane methods, which, at present, begin to find wide application in the housing and communal services and domestic industries. Despite this, there are quite a lot of issues related to increasing the efficiency of membrane separation processes, in particular, reducing the water consumption for own needs [1-17].

\section{Materials and methods}

The operating costs of membrane plants include the costs of chemical reagents for washing membrane elements, the cost of replacing them at the end of their service life and, of course, the costs for their own needs. In ultrafiltration installations, due to the use of dead-end filtration, own needs are added up from the costs of direct and backwashing, as well as regular chemical enhanced washings to restore the performance of the membranes. In installations of reverse osmosis, in addition to washings, the percentage of concentrate output is taken into

\footnotetext{
* Corresponding author: ekatsamar@yandex.ru
} 
account. The question of the excessive amount of concentrate of reverse osmosis plants in the operation of baromembrane water treatment systems is still an important issue, because, as practice shows, the water consumption for own needs in real operating conditions can differ significantly from the values, estimated and regulated by the manufacturers of the plants $[10,15]$.

To investigate this issue, an analysis of the operation of the combined membrane filtration installation was carried out, including an ultrafiltration unit ( 3 blocks of 40 tons per hour) and a reverse osmosis unit ( 3 blocks of 33 tons per hour). The total productivity is 90 tons per hour.

When calculating own needs for the ultrafiltration units, it was taken into account that every 40 minutes of operation, automatic water washing (direct - reverse - direct) is performed. Direct washing was carried out with the initial water for 30 seconds at a flow rate of $40 \mathrm{t} / \mathrm{h}$. Backwashing was carried out with filtrate for 18 seconds (flow rate $170 \mathrm{t} / \mathrm{h}$ ). Based on the results of the tests, a calculation was carried out, which showed that the water flow for washing was 1.51 tons, and there were 33 washings per unit per day.

Table 1 shows the number of washings, taking into account the actual operating time in April 2017. The loss of water in this case was 2380.76 tons.

Table 1. The number of water washings, taking into account the actual operating time.

\begin{tabular}{|c|c|c|}
\hline Installation number & Number of washings, pcs. & Operating time, hrs. \\
\hline UUF No 1 & 521 & 375 \\
\hline UUF No 2 & 528 & 380 \\
\hline UUF No 3 & 526 & 377 \\
\hline
\end{tabular}

Enhanced chemical cleaning was performed after 8 hours of operation in semi-automatic mode for 30 minutes. The calculation showed that in this case the water losses were 4.2 tons for one chemical washing. The total water losses, taking into account the actual operating time in April 2017, amounted to 581.6 (hourly losses $0.8 \mathrm{t} / \mathrm{h}$ ).

Thus, the total own needs of the ultrafiltration installation were at the level of 2962.36 tons.

The capacity of the reverse osmosis plant KROS ranged from 31 to $33 \mathrm{t} / \mathrm{h}$. At the same time, from each installation, the concentrate consumption was 5 tons per hour. After 120 hours of operation, each KROS was washed with circulation for 30 minutes (water flow was 400-500 liters per washing). Table 2 presents the main technological parameters of the reverse osmosis plant operation during the testing period in April 2017.

In the operation of the reverse osmosis plant, water losses with concentrate amounted to 4158 tons, or 5.6 tons per hour. The total losses in the operation of the combined membrane plant as a whole amounted to: $2,962+4,158=7,120$ tons. Based on the test results, it can be concluded that of the general needs of the chemical water treatment plant $(12,637$ tons), the needs of the ultrafiltration and reverse osmosis installation $(7,120$ tons) were $56 \%$, and the origin of the remaining $44 \%$ of water losses remained unknown.

The growth of own needs can be explained by the decrease in loads and the need for chemically cleaned water and, as a result, the reduction in the number of operating hours of installations in the summer period [5].

At this time, reverse osmosis plants operated at shorter intervals, therefore, more switching occurred. The analysis of operation of the system showed that with each switchon, the reverse osmosis plant dumped 1.2 tons of water before reaching the operating parameters. 
Table 2. Main technological indicators of operation of the reverse osmosis plant during the testing period in April 2017.

\begin{tabular}{|c|c|c|}
\hline Plant No & Operation time, hours & $\begin{array}{c}\text { The yield of the concentrate, } \\
\text { tons / month }\end{array}$ \\
\hline KROS No 1 & 210 & 1,046 \\
\hline KROS No 2 & 112 & 556 \\
\hline KROS No 3 & 512 & 2,556 \\
\hline
\end{tabular}

\section{Results}

In order to reduce the water consumption for the own needs of the combined membrane plant, the reverse osmosis installation of the unit No. 2 was conserved during the summer period from 18.06.2017 to 12.09.2017.

During the period of conservation in the non-heating period (Figure 1), the peak values of water consumption for the needs of the water treatment plant decreased that confirmed the effectiveness of its implementation.

In practice, in real-life membrane plants under variable conditions and non-permanent loads, water consumption for own needs is often more than indicated by the producers due to the periodic operation of the installation. At the same time, the costs of the ultrafiltration unit always remain conditionally constant. This phenomenon can be explained by frequent switching and washings of the reverse osmosis systems, aging of membranes and, as a result, longer washings before switching on, as well as decreasing the degree of permeate withdrawal to ensure a constant quality of water at the outlet of the plant.

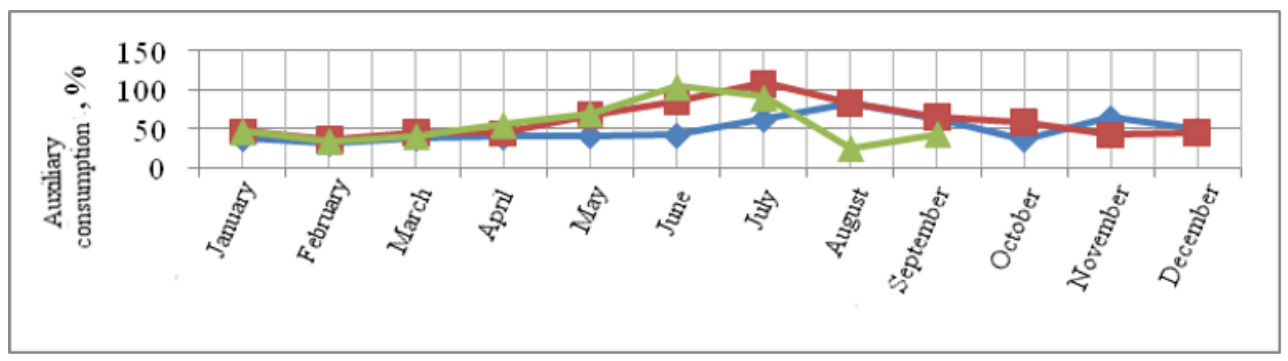

Fig. 1. Changing the chemical water treatment system's own needs during the year.

To analyze the causes of the effect of membrane aging on water consumption for the needs of a reverse osmosis plant, a reverse osmosis element was tested in a laboratory unit under the following conditions: a model solution of sodium chloride in water with a mass fraction of $500 \mathrm{mg} / \mathrm{dm} 3$, a temperature of $25^{\circ} \mathrm{C}$, a working pressure of 8 atmosphere, source water-tap water, close to the quality of the filtrate of the ultrafiltration unit.

The result was the following: selectivity $-98 \%$ at a capacity of $1901 / \mathrm{h}$.

After the tests, a visual inspection of the membrane elements revealed a strong contamination at the ends of the element with a dark substance. The autopsy revealed an average contamination of the membrane surface with a loose substance similar to clay, whose moisture content was $86 \%$, and the total amount of contaminants in the element in terms of the dry residue was $6.8 \mathrm{~g}$. Chemical analysis of the membrane contamination showed the following results (Table 3 ).

Table 3. Chemical analysis of the membrane contamination.

\begin{tabular}{|c|c|}
\hline Indicator & Content, \% \\
\hline Polysilicates & 42 \\
\hline Organics & 31.5 \\
\hline
\end{tabular}




\begin{tabular}{|c|c|}
\hline Iron & 13.4 \\
\hline Calcium & 6 \\
\hline Magnesium & 1.8 \\
\hline Sulphates & 0.76 \\
\hline Manganese & 0.09 \\
\hline Copper & 0.09 \\
\hline
\end{tabular}

The results of the analysis led to the conclusion that water with a high content of iron hydroxide, polysilicates, silicic acid and organic matters was supplied to the reverse osmosis unit.

For the most effective regeneration of membranes and prolongation of their service life, based on the results of autopsy, an intensive washing of membranes is suggested in several stages:

- $2 \%$ solution of sodium tripolyphosphate for 1.5 hours at $30^{\circ} \mathrm{C}$;

- purified water for 0.5 hours;

- an aqueous solution containing $2 \%$ ammonium fluoride and $1 \%$ citric acid for 1.5 hours at $30^{\circ} \mathrm{C}$.

Such regeneration of membrane elements can be carried out in situ while reducing their productivity by $10 \%$ from the initial one after reaching the operating mode.

In actual operation of the reverse osmosis unit, an increase in the specific electrical conductivity of the permeate is seen as the aging index of membranes.

\section{Discussion}

Creation of water treatment systems consisting only of plants based on the membrane separation technology, such as ultrafiltration and reverse osmosis (i.e. use of the integrated membrane technologies) is advisable in the case of membrane technologies for newly built water treatment plants. This is due to the fact that the use of membrane systems in new construction significantly reduces the required number of production areas because of the compact arrangement of equipment, as well as the absence of reagent farms.

In the case of reconstruction of the existing water treatment systems, the consumer will inevitably encounter increased water consumption for own needs during their operation, since it will often be difficult to predict the actual operational performance of the reconstructed water treatment plant, and they will be very different in each specific case. The use of pilot systems in such situations before the introduction of a full-fledged installation can help to obtain sufficiently accurate and complete information and estimate the actual operating parameters of the membrane plant, which will result in significant cost savings due to a competent forecast of real losses in the further operation of industrial membrane systems.

\section{Conclusions}

Improvement of membrane water treatment systems with regards to reducing the values of water consumption for own needs and their compliance with regulated norms can be realized in the following directions $[4,6]$ :

1. Revision of normalized values of own needs in a big way taking into account an annual influence of aging of membranes on consumption of water for own needs of membrane installations.

2. Changing the existing mode of operation of membranes (however, it should be kept in mind that changing the operating mode of membrane systems in favor of reducing water consumption for own needs can lead to an acceleration of the aging process of the membrane elements). 
3. Ensuring a uniform load of water treatment equipment during the whole period of operation by reducing the number of its switching, and for a period of minimum loads, providing for the temporary decommissioning of reserve blocks with the help of conservation measures.

4. To reduce operating costs, it is advisable to consider technologies for sharing the membrane separation of aqueous solutions in the preparation of water and traditional technologies (in particular, ion exchange).

\section{References}

1. S. S. Gavrilenko, Research and development of approaches to the design of water treatment plants for combined-cycle power plants (Moscow, 2014)

2. S. P. Zhuravlev, Development of technological schemes for processing natural waters and spent regenerative solutions of the VPU with the isolation of insoluble compounds (Moscow, 2006)

3. A. V. Nakhabo, E. V. Samarkina, Increasing energy efficiency in Siberia, 12-14 (2014)

4. A. V. Nakhabo, E. V. Samarkina, Increasing energy efficiency in Siberia, 34-36 (2015)

5. A. A. Panteleev, V. F. Ochkov, S. S. Gavrilenko, Energy Saving and Water Treatment, 4(90), 11-16 (2014)

6. A. V. Nakhabo, V. G. Gudzenko, A. N. Samarkina, E. V. Samarkina, Collection of articles of the All-Russian Scientific and Practical Conference, 96-100 (2017)

7. A. V. Efremov, Kinetics of the process of separation of solutions by the reverse osmosis method using cellulose acetate and borosilicate membranes (Ivanovo, 2014)

8. A. A. Panteleev, 6th International Water and Chemical Forum (2013)

9. S. P. Zhuravlev, Development of technological schemes for processing natural waters and spent regenerative solutions of the VPU with isolation of insoluble compounds (Moscow, 2006)

10. N. D. Chichirova, A. A. Chichirov, A. A. Filimonova, S. R. Saitov, Heat Engineering, 12, 67-77 (2017)

11. S. L. Gromov, Heat Engineering, 6, 49-58 (2014)

12. A. P. Andrianov, A. G. Pervov, Series. Critical technologies. Membranes, 2(18) (2003)

13. V. A. Kishnevsky, L. V. Petrikevich, Proceedings of the Odessa Polytechnic University, 1(31) (2009)

14. I. B. Rejderman, Water Supply and Sanitary Engineering, 3 (2010)

15. I. S. Balaev, G. G. Kuchma, O. B. Yakovenko, A. V. Erofeev, S. K. Dobrovsky, Energy Saving and Water Treatment, 3(71), 15-19 (2011)

16. T. V. Kurochkina, Energy Saving and Water Treatment, 4(78), 20-23 (2012) 